Eur. J. Mineral.

2019, 31, 289-299

Published online 1 April 2019

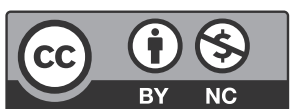

Mineral reactivity:

from biomineralization and Earth's climate evolution to $\mathrm{CO}_{2}$ capture and monument conservation

\title{
Baryte cohesive layers formed on a (010) gypsum surface by a pseudomorphic replacement
}

\author{
Cristina RUIZ-AGUDO ${ }^{1}$ **, Pedro ÁllVAREZ-LloreT ${ }^{2}$, Fulvio DI LORENZO ${ }^{3}$, \\ DENIS GEBAUER ${ }^{1}$ and Christine V. PUTNIS ${ }^{4,5}$
}

\author{
${ }^{1}$ Department of Chemistry, Physical Chemistry, University of Konstanz, Universitätsstr. 10, 78464 Konstanz, Germany \\ *Corresponding author, e-mail: criss_ru@ hotmail.com \\ ${ }^{2}$ Department of Geology, University of Oviedo, Jesús Arias de Velasco s/n, 33005 Oviedo, Spain \\ ${ }^{3}$ Department of Mineralogy and Petrology, University of Granada, Fuentenueva s/n, 18071 Granada, Spain \\ ${ }^{4}$ Institut für Mineralogie, Corrensstrasse 24, 48149 Münster, Germany \\ ${ }^{5}$ Department of Chemistry, Curtin University, 6845 Perth, Australia
}

\begin{abstract}
The mineral replacement of gypsum $\left(\mathrm{CaSO}_{4} \cdot 2 \mathrm{H}_{2} \mathrm{O}\right)$ by baryte $\left(\mathrm{BaSO}_{4}\right)$ is relevant to technological and industrial applications, including its use as a plaster or stone consolidant in cultural heritage conservation. In the present study, we provide experimental evidence suggesting that, during the interaction of gypsum cleavage surfaces with barium-bearing solutions, a pseudomorphic replacement takes place and results in the formation of a crystallographically oriented baryte layer. This mineral replacement process is favoured by the porosity generated, due to the differences in molar volume and solubility between parent and product sulfate phases, allowing the progress of the reaction. The homogeneous micrometre-sized layer of baryte occurs most likely via a fluid-mediated interface-coupled dissolution-precipitation mechanism. A certain degree of crystallographic control on the polycrystalline $\mathrm{BaSO}_{4}$ product layer by the structure of the parent substrate (gypsum) is confirmed by electron microscopy observations and X-ray diffraction analyses. The structural control exerted by the cleavage gypsum surface on the baryte layer can be defined by the epitactic relationship: Gyp (010) \| Bar (010). The formation of baryte increases with reaction time until passivation occurs at the replacement interface, probably due to a decreased porosity and loss of connectivity that thereby prevents further reaction. The investigation of these processes occurring on freshly cleaved single crystals of gypsum were complemented by studying the replacement of polycrystalline gypsum cubes, showing a homogeneous baryte surface layer on the sample. The results of this study thus offer interesting insights into the application of the replacement of gypsum by baryte as a conservation method for gypsum sculptures and plasterwork, increasing their resistance against water and humidity while preserving the surface features of the original mineral substrate.
\end{abstract}

Key-words: baryte; gypsum; epitaxy; pseudomorphic replacement; conservation.

\section{Introduction}

The importance of gypsum in both natural and industrial environments has motivated a wide research interest on the fundamental aspects of gypsum crystallization over the last century (Ostroff, 1964; Zen, 1965; Hardie, 1967; Bosbach \& Rammensee, 1994; Hall \& Cullen, 1996; Lasaga \& Luttge, 2001; Freyer \& Voigt, 2003; Fan \& Teng, 2007; Van Driessche et al., 2010, 2012; Teng et al., 2011; BurgosCara et al., 2016). In nature, gypsum (calcium sulfate dihydrate, $\left.\mathrm{CaSO}_{4} \cdot 2 \mathrm{H}_{2} \mathrm{O}\right)$ is the most abundant sulfate mineral on the Earth's surface (e.g., evaporite deposits; Watson, 1979) and plays a significant role in global sulfur and redox cycles (Alonso-Azcárate et al., 2001, 2006). From a technological point of view, gypsum is commonly used as construction material (e.g., mortars, blocks, and cement additive) as well as a fertilizer and soil conditioner in agriculture (Stewart,
1989), and many other applications. However, gypsum formation is not always beneficial and can pose major problems due to economical losses generated by the deposition of gypsum scales in pipes and/or industrial processes (Ahmed et al., 2004).

The pseudomorphic replacement of gypsum by baryte also could have implications in the reconstruction of the formation of our planet. Archean rocks are the only existing source of information about the early evolution of the Earth. Records of Earth's primitive atmosphere, hydrosphere, biosphere, oceans and evidence of the earliest primitive life-forms have been widely investigated in Archean rocks via isotopic measurements on baryte deposits. One of the most studied Archean formations is located in the Warrawoona group of the Pilbara Province (Western Australia). These rocks (3.515-3.458 Ga; Buick \& Dunlop, 1990) have experienced only slight deformation and very-low-grade 
metamorphism (Buick et al., 1995), hence they are extremely useful for investigations of early Earth characteristics. Archean bedded sulfate deposits in Pilbara, consisting of baryte, are suggested to be formed by the replacement of original evaporitic gypsum deposits (Lambert et al., 1978; Buick \& Dunlop, 1990). Petrographic evidence such as measurements of interfacial angles of baryte crystals suggest that they result from diagenetic replacement of an original gypsum sequence. Understanding the formation mechanism of these baryte deposits from original gypsum is crucial since diagenetic processes occurring in these barytes may change the isotopic signature and affect the reconstruction of the Archean conditions on the Earth.

From an application perspective, gypsum is used worldwide as a plaster building material on interior coatings and surfaces (such as walls and ceilings) due to its inexpensive nature, rapid installation, durability and protective behaviour. The extraordinary capabilities of gypsum plaster have been well-known for centuries. It was used by the ancient Egyptians to plaster the pyramid of Cheops (Regourd et al., 1988) and in the sophisticated Nasrid plasterworks (Dominguez-Vidal et al., 2012) that decorate the Alhambra Palace (Granada, Spain). However, when gypsum plasterwork is exposed to humidity (e.g. rain, condensation or rising damp), it is highly prone to degradation caused by the relatively high solubility of this sulfate phase and the high open porosity $(41-65 \%)$ in the resulting material (Blasco-López \& Alejandre Sánchez, 2013) that allows moisture to penetrate, providing an ideal environment for fungal and algal growth and further enhanced degradation. Therefore, strategies for preservation and consolidation of gypsum plaster need to be developed for preventing its degradation. Acrylic, epoxy or polyvinyl polymers have been tested as plaster or stone consolidants; nevertheless, these materials present some problems related to physical and chemical incompatibilities with the inorganic substrate (Jroundi et al., 2014). Other recent approaches envisage the use of carbonatogenic bacteria that induce $\mathrm{CaCO}_{3}$ mineralization as an alternative bioconsolidation method for archaeological gypsum plasters (Jroundi et al., 2014).

Here, mineral replacement reactions using Ba-bearing solutions are presented as a possible consolidation alternative for gypsum plaster. In such replacement processes, a mineral A reacts with a fluid undersaturated with respect to A, hence it starts to dissolve, resulting in a new fluid composition at the fluid-mineral interface that then may become supersaturated with respect to a new, more stable mineral phase B that can precipitate (Ruiz-Agudo et al., 2014). Depending on the rate-controlling step between dissolution and precipitation, the minerals, both parent $\mathrm{A}$ and product $\mathrm{B}$, could be spatially separated (i.e., precipitation is the rate-controlling step) or mineral $B$ nucleates on the surface of the dissolving mineral A (i.e., dissolution is the ratecontrolling step; Putnis, 2009). Coupling at the reaction interface between dissolution and precipitation leads to pseudomorphic mineral replacement in which the external volume and hence the external crystalline morphology of mineral $\mathrm{A}$ is preserved during the replacement by mineral B. The generated interconnected porosity in mineral phase $\mathrm{B}$, due to differences in molar volume and relative solubility between phases A and B (Putnis, 2002, 2009; Putnis \& Putnis, 2007; Pollok et al., 2011; Ruiz-Agudo et al., 2014), permits fluid infiltration and allows the replacement process to continue. In the case of a crystallographic structural matching between mineral $\mathrm{A}$ and the newly formed phase B (epitaxy), nucleation would be enhanced and crystallographic information is transferred from one phase to another (Prieto et al., 2003; Álvarez-Lloret et al., 2010).

In the present study, we aim for a better understanding of the replacement process that results from the interaction between gypsum with Ba-bearing solutions and results in the formation of a stable baryte phase. This phase has a solubility several orders of magnitude lower than gypsum, and could therefore significantly increase the resistance of gypsum plasters to further chemical weathering. Similarly, baryte is harder (Mohs hardness $H \sim 3.5$ ) than gypsum $(H=2)$, which would make gypsum plasters more resistant to physical-mechanical weathering. The replacement was studied on the cleavage gypsum surface (010) and in polycrystalline cubes of gypsum at ambient temperature and pressure. The use of complementary analytical techniques on reacted samples allowed us to obtain a deeper knowledge of this mineral replacement via a dissolution-precipitation reaction and to assess its suitability as a gypsum plaster conservation method.

\section{Materials and methods}

\subsection{Replacement reactions on gypsum single crystals and polycrystalline cubes}

Replacement experiments were performed at room temperature $\left(22 \pm 2{ }^{\circ} \mathrm{C}\right)$ in separate plastic sealed containers $(50 \mathrm{~mL})$. Two replicas were carried out for each condition. Optically clear gypsum single crystals $(0.095 \pm 0.010 \mathrm{~g}$ average weight, $c a .5 \times 6 \times 1 \mathrm{~mm}$ in size) were used for the experiments. The crystals were cleaved immediately before each experiment to obtain fresh (010) gypsum surfaces. The crystal sections were cut perpendicular to the (010) surfaces, creating a striated surface (i.e. normal to the cleavage surface, zigzag line in Fig. 1). It should be noted that in the single crystals used in this study, the (010) surface was the only real crystallographic gypsum surface and the perpendicular edges of the crystals were created artificially by cutting. The characteristics of the gypsum crystal habit makes it difficult to obtain a representative number of natural crystals that develop other crystallographic faces with suitable dimensions for the experiments. The crystals were cleaved and the edges were cut (aiming a $90^{\circ}$ ) in order to work with samples of similar sizes (and weights) in all experiments.

In Table 1, the experimental conditions used for this study are summarized. The $\mathrm{BaCl}_{2}$ solutions $(1-250 \mathrm{mM})$ were prepared immediately prior to each experimental run from stock solutions made from solids from Merck Suprapur min. 99.995\% $\left(\mathrm{BaCl}_{2}\right)$ and deionized water (Milli-Q, resistivity $>18.2 \mathrm{M} \Omega \mathrm{cm}$ ). The crystals were held in 

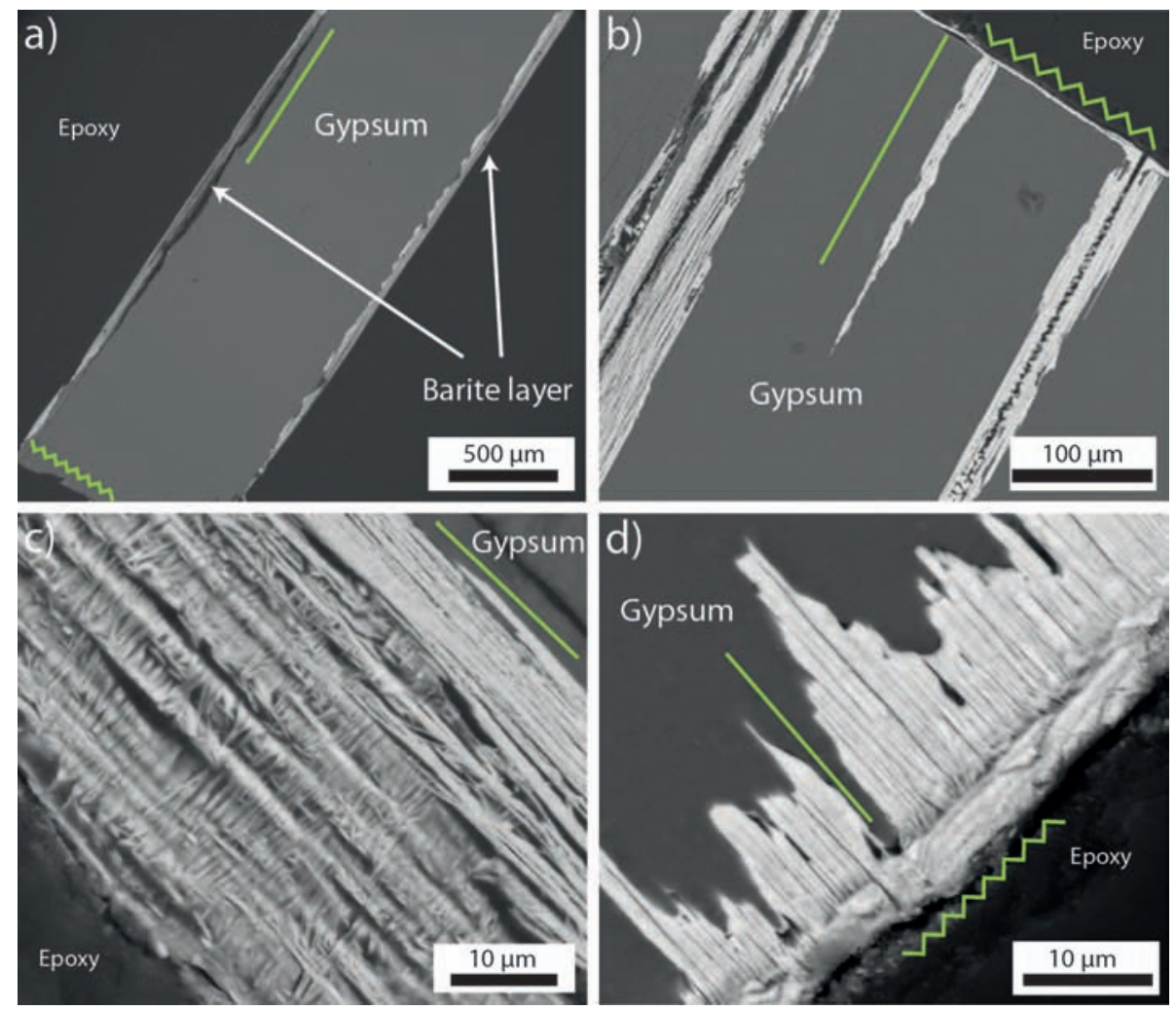

Fig. 1. Back-scattered electron (BSE) images of cross-section of partially replaced gypsum crystals after $24 \mathrm{~h}$ reaction time (250 mM $\mathrm{BaCl}_{2}$ ). The green continuous line is parallel to (010) gypsum surfaces and the zigzag line represents the artificially created gypsum striated surfaces. (a) General view of the pseudomorphic baryte layer formed (white outer rim indicated by arrows). (b) Baryte replacement layer along the striated gypsum surfaces created during sample preparation. The replacement along preexisting cracks that exposed (010) surfaces is also observed in this image. (c) Higher-magnification image on the replaced layer showing clear preferred orientation of the baryte crystals with respect to the gypsum (010) surface. (d) High-magnification image of the replacement on the striated surfaces.

$50 \mathrm{~mL}$ solution for reaction times ranging from $30 \mathrm{~min}$ to $168 \mathrm{~h}$. After the experiments, the crystals were removed from the solution, washed with ethanol, and dried at $40^{\circ}$ $\mathrm{C}$ for $24 \mathrm{~h}$. After a first screening of the barium concentrations, $250 \mathrm{mM}$ was selected for time evolution experiments. The final solutions from those experiments were filtered and then analysed for $\mathrm{Ca}$ and $\mathrm{S}$ concentration using a Varian inductively coupled plasma optical emission spectrometer (ICP-OES). The corresponding two replicas for the selected conditions were analysed and an average value was calculated. The extremely high concentration of initial $\mathrm{Ba}$ $(250 \mathrm{mM})$ compared with the amount of $\mathrm{BaSO}_{4}$ precipitated and the slight variability of the gypsum crystal sizes used made it impossible to obtain any information from Ba concentration measurements. Moreover, due to the variability in the dimensions of the gypsum crystal used for our experiments, the calcium and sulfur released to the solution with time cannot be quantitatively assessed. However, these elemental analyses can be qualitatively used to study any trend followed during replacement reactions.

The replacement process of gypsum by baryte studied on single crystals was complemented by using polycrystalline samples to describe a more realistic scenario, aiming at the application of gypsum plaster conservation. Polished cubes (10 mm side length) of polycrystalline gypsum inter- acted with $50 \mathrm{~mL}$ of $\mathrm{BaCl}_{2}$ solution $(100,250$ and $560 \mathrm{mM})$ for different reaction times $(1,24$ and $96 \mathrm{~h})$. The $\mathrm{BaCl}_{2}$ solutions were prepared similarly to the experiments carried out on gypsum single crystals. The experiments were conducted in sealed plastic containers at $22 \pm 2{ }^{\circ} \mathrm{C}$. After the experiments, the cubes were removed from the solution, washed with ethanol, and dried at $40{ }^{\circ} \mathrm{C}$ for $24 \mathrm{~h}$.

\subsection{Characterization methods}

Selected representative samples were examined with scanning electron microscopes (SEM: JEOL 6610-LV and FESEM: Zeiss SUPRA40VP) equipped with backscattered electron (BSE) and energy-dispersive X-ray (EDX) detectors. Gypsum single crystals and polycrystalline cubes were embedded in epoxy after the experiments. Cross sections were prepared by cutting and polishing the embedded samples using a non-aqueous liquid (i.e., decane).

The reacted gypsum single crystals were analysed with a confocal Raman spectrometer (Horiba Jobin Yvon XploRA) operating with a Nd:YAG laser $(532.09 \mathrm{~nm})$. For the spectral measurements, a $100 \times$ objective was used with a confocal aperture of $500 \mu \mathrm{m}$ and an acquisition time of $3 \times 60 \mathrm{~s}$. The depth resolution from the surface was a few micrometres. The scattered light was collected in a 
Table 1. Experimental conditions used in gypsum interaction with $\mathrm{BaCl}_{2}$.

\begin{tabular}{|c|c|c|c|}
\hline Gypsum sample & $\mathrm{BaCl}_{2}$ initial $(\mathrm{mM})$ & Duration (h) & Layer thickness $(\mu \mathrm{m})$ \\
\hline Single crystal & 1 & 24 & No layer formed + single particles \\
\hline Single crystal & 10 & & No layer formed + single particles \\
\hline Single crystal & 50 & & Non-continuous layer + single particles \\
\hline Single crystal & 250 & & $39 \pm 5$ \\
\hline Single crystal & 560 & & $55 \pm 7$ \\
\hline Single crystal ${ }^{*}$ & & 120 & $61 \pm 5$ \\
\hline Single crystal* & & 168 & $55 \pm 4$ \\
\hline Single crystal* & 250 & 0.5 & Not measured \\
\hline Single crystal* & & 1 & Not measured \\
\hline Single crystal* & & 2 & Not measured \\
\hline Polycrystalline & 100 & 24 & $10 \pm 3$ \\
\hline Polycrystalline & 250 & & $20 \pm 5$ \\
\hline Polycrystalline & 560 & & $80 \pm 10$ \\
\hline Polycrystalline & 250 & 1 & $12 \pm 3$ \\
\hline Polycrystalline & 250 & 96 & $25 \pm 10$ \\
\hline
\end{tabular}

*Samples used for ICP-OES measurements.

$180^{\circ}$ backscattering geometry and analysed with a chargecoupled device (CCD) detector after being dispersed by a grating of 1200 grooves $/ \mathrm{mm}$ and passed through a $100 \mu \mathrm{m}$ entrance slit. Prior and after every measurement of the reacted samples, a silicon standard was measured for corrections of the drift using the $520.7 \mathrm{~nm}$ Raman band position.

A Philips X'Pert X-ray powder diffractometer equipped with $\mathrm{Cu} K \alpha$ radiation source $(\lambda=1.5405 \AA)$ was used to identify the layer formed on the gypsum (010) crystal surfaces. Working conditions were set at $45 \mathrm{kV}$ voltage and $40 \mathrm{~mA}$ current intensity. Selected single-crystal samples were mounted in the diffractometer after drying to identify the replacement layer. The rest of the samples were crushed using an agate mortar and pestle to check whether baryte was formed. The XRD measurements were collected between 5 and $60^{\circ} 2 \theta$ (only the range from 10 to $50^{\circ}$ was shown in for clarity) with a step size of $0.092 \% \mathrm{~min}$ for a total time of $1 \mathrm{~h}$.

Two-dimensional X-ray diffraction (2D-XRD) patterns were recorded using an X-ray single-crystal diffractometer (Bruker D8 VENTURE) equipped with an area detector (PHOTON 100). The diffractometer working conditions for the experiments were: Mo $K \alpha(\lambda=0.7093 \AA), 50 \mathrm{kV}$ and $30 \mathrm{~mA}$. The $2 \mathrm{D}$-XRD patterns were registered in reflection mode setting the $\omega$ and $2 \theta$ diffractometer angles at $10^{\circ}$ and $20^{\circ}$, respectively, while rotating the sample around the $\Phi$ angle (a frame every $5^{\circ}$ step) with a pinhole collimator $0.5 \mathrm{~mm}$ in diameter and an exposure time of $10 \mathrm{~s}$ per frame. The 2D-XRD patterns and pole figures representing the three-dimensional gypsum and baryte crystal orientations at specific $(h k l)$ crystallographic planes were calculated using the XRD2DScan software (Rodriguez-Navarro, 2006). Furthermore, the degree of misorientation of the baryte crystals was determined from the angular breadth of the arcs displayed in the intensity profile $(\psi$-scan) along the Debye-Scherrer ring associated to each $h k l$ reflection. The wider the band, the greater the degree of scattering in the preferential orientation of the baryte crystals in the replaced layer.

\section{Results}

The overall results show how baryte cohesive layers form as a result of a pseudomorphic replacement reaction controlled by the (010) cleavage gypsum surface. The FESEM observations and EDX analyses of cross-sections of partially reacted samples show that gypsum is pseudomorphically replaced by $\mathrm{BaSO}_{4}$ when single crystals and polycrystalline cubes are in contact with a $\mathrm{BaCl}_{2}$ solution. The formed baryte layers were also characterized by Raman spectroscopy and XRD measurements on reacted samples. The crystallographic relationships between the (010) gypsum surface and the replacing baryte layer were further investigated in selected single-crystal experiments by means of 2D-XRD analyses, which confirmed the crystallographic control that the gypsum surface exerts on the formation of baryte.

\subsection{Gypsum single-crystal experiments}

The investigations on gypsum single crystals show that the progress of the replacement process was highly enhanced in 
the direction perpendicular to the (010) gypsum surfaces in comparison with the striated surfaces of the cut crystal surfaces (Fig. 1a and b). While in the direction perpendicular to a gypsum (010) surface the baryte replacement layer has a thickness between 30 and $50 \mu \mathrm{m}$ on average, in the striated surfaces the replacement only progressed 5-10 $\mu \mathrm{m}$ (Fig. 1b). In addition, the morphology of the two baryte-replacement layers differs significantly. Also, the advancement of the replacement within pre-existing cracks (in the striated surfaces) that exposed (010) gypsum surfaces to the Ba-bearing fluid is relatively enhanced (Fig. 1b).

Observing more closely the baryte layer perpendicular to the (010) gypsum surface (Fig. 1c), a clear orientation of the baryte crystals formed at the outer surface of the replacement layer can be distinguished. In addition, a clear evolution of the microscale porosity within the replacement layer can be observed in the cross sections (Fig. 1c). By the time FESEM images were acquired (several days), the outer $\mathrm{BaSO}_{4}$ layer showed a high porosity that is progressively reduced towards the inner part of the replacement front. Thickness measurements of the $\mathrm{BaSO}_{4}$ replacing layer over time show no substantial difference between samples immersed for three days and samples immersed for seven days, which indicates a probable passivation of the replacement process.

The evolution of $\mathrm{Ca}$ concentration over time in the bulk fluid showed that the amount of $\mathrm{Ca}$ released increased from 0.5 to $72 \mathrm{~h}$ and then slightly decreased at longer reaction times (Fig. 2). Sulfur concentrations were lower than $\mathrm{ppb}$ or under the detection limit in most of the ICP-OES measurements. The $\mathrm{Ca}$ concentration measured by ICP-OES after $24 \mathrm{~h}$ showed that in this period approximately $10 \%$ of the gypsum crystal has been dissolved. Due to the large solubility difference between parent and product phases when gypsum $\left(K_{\mathrm{sp}}=10^{-4.5}\right)$ is replaced by baryte $\left(K_{\mathrm{sp}}=10^{-10}\right)$, if equilibrium is reached with respect to baryte, a very small sulfate concentration $\left(\sim 10^{-8} \mathrm{M}\right.$, calculated with speciation software Phreeqc; Parkhurst \& Appelo 1999 ) is released to the $250 \mathrm{mM}$ barium solution.

As it was stated above, there was a significant difference between the replacement layer in the direction perpendicular to the (010) gypsum surface and on the striated surfaces of the crystal (formed artificially during sample preparation). The baryte layer formed at the cut surface is less porous than the layer perpendicular to the gypsum (010) surface and the advancement of the replacement was considerably slower (Fig. 1d).

The EDX (Fig. 3a), Raman (Fig. 3b) and XRD (Fig. 3c) analyses on partially replaced single crystals of gypsum confirmed the presence of a baryte replacement layer on the gypsum (010) surface. After $1 \mathrm{~h}$, baryte could be already detected by XRD on crushed reacted samples. The onedimensional XRD pattern of non-crushed single-crystal samples shows an apparent preferred orientation of the baryte layer formed on the (010) gypsum surface. Indeed, FESEM observations of the surface of the replaced crystals on the surface perpendicular to (010) gypsum surface show a particular orientation of the baryte crystals after 1 day (Fig. 4a) and 3 days (Fig. 4b) reaction time.

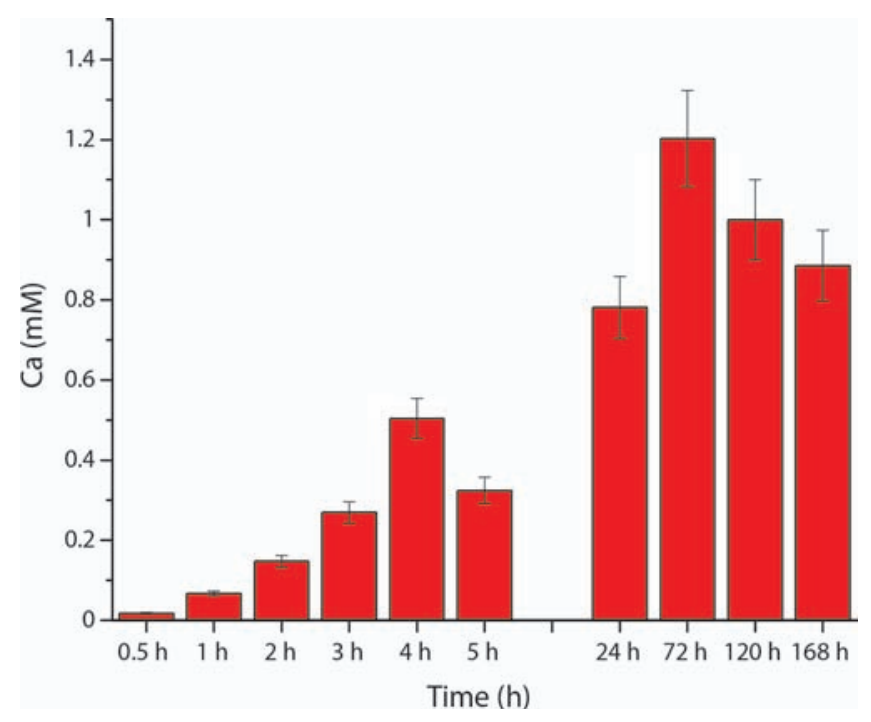

Fig. 2. Solution calcium content after different reaction times in the experimental runs, as measured by ICP-OES.

The 2D-XRD patterns show the presence of strong and well-defined diffraction spots corresponding to the gypsum crystal surface and several Debye-Scherrer diffraction rings related to the baryte polycrystalline replacement layer (Fig. 5a). Superimposed on these diffraction rings, the intensity is concentrated in arcs, which indicates that a significant fraction of the baryte crystals has a preferential orientation. The gypsum-baryte replacement is also confirmed by the radial integration of the diffraction intensities within the 2D-RXD in a one-dimensional ( $2 \theta$ scan profile) pattern (Fig. 5b).

The preferential orientation of the baryte replacement crystals in relation to the (010) gypsum surface was further characterized by the determination of the pole figures for $h \mathrm{kl}$ reflections obtained from the 2D-XRD pattern analyses (Rodriguez-Navarro, 2006). Figure 6 displays the 2D-XRD results showing the pole figures $(\mathrm{PF})$ for the analyses of the crystallographic relationships between gypsum and baryte in the experiments carried out after 1 day of reaction time. The PF for gypsum 020 reflection (Fig. 6a) indicates that the sample is properly oriented in the plane of the cleavage surface. Figure $6 \mathrm{~b}$ displays the combined PF for 020 and 301 reflections of the baryte replacement crystals showing a centred maximum corresponding to the 020 reflection (co-oriented with the gypsum surface) and two maxima related to the 301 reflection and tilted approximately $90^{\circ}$ from the PF centre. Confirming this preferential baryte orientation, PFs for the combined $200+011$ and the $303+321$ reflections for baryte crystals are represented in Fig. 6c and d, respectively (see figure caption for further detail). These 2D-XRD analyses confirmed the crystallographic orientation relationships between the gypsum cleavage surface and the baryte replacement crystals as follows: Gyp (010) \| Bar (010). This epitaxy can be characterized taking into account the matching between these two planes along the [100] and [001] directions, respectively (Fig. 7). The $\mathrm{Ca}-\mathrm{Ca}$ and $\mathrm{S}-\mathrm{S}$ distances in Gyp (010) along [100] 

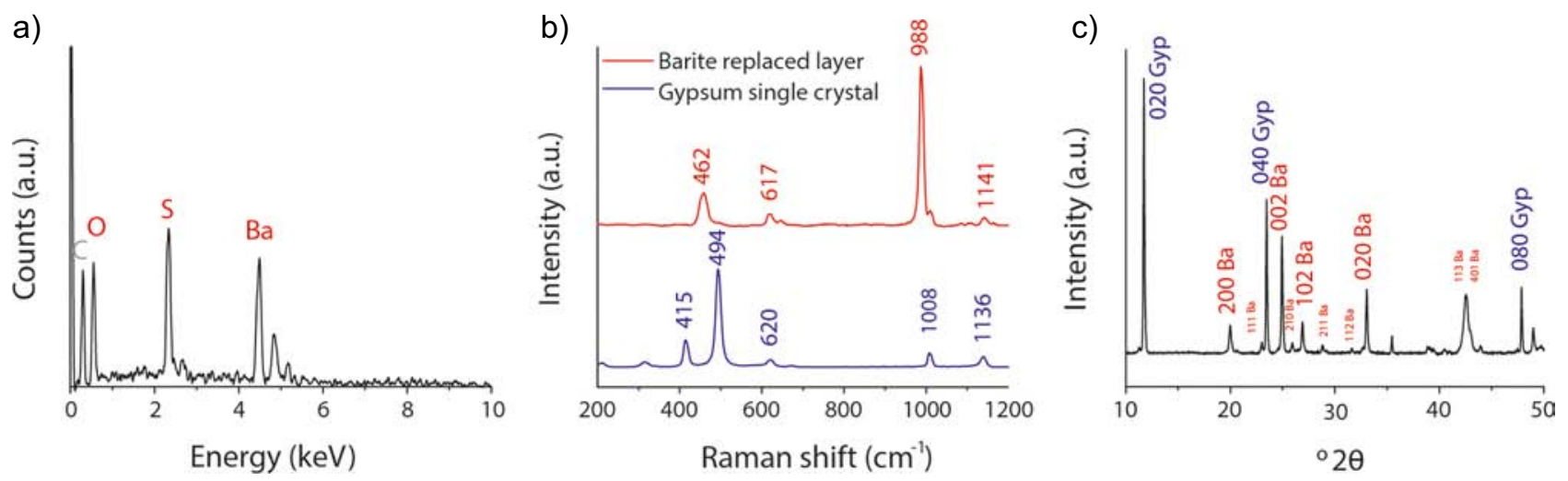

Fig. 3. (a) Representative EDX (Energy Dispersive X-ray) analysis of baryte layer formed after $24 \mathrm{~h}\left(250 \mathrm{mM} \mathrm{BaCl}_{2}\right) \mathrm{measured}$ in cross-sections of the partially replaced crystals. (b) Raman spectra of cross-sections of gypsum crystals partially replaced by baryte $(250 \mathrm{mM} \mathrm{BaCl})_{2}$. (c) XRD pattern of a single crystal after a $24 \mathrm{~h}$ experiment.
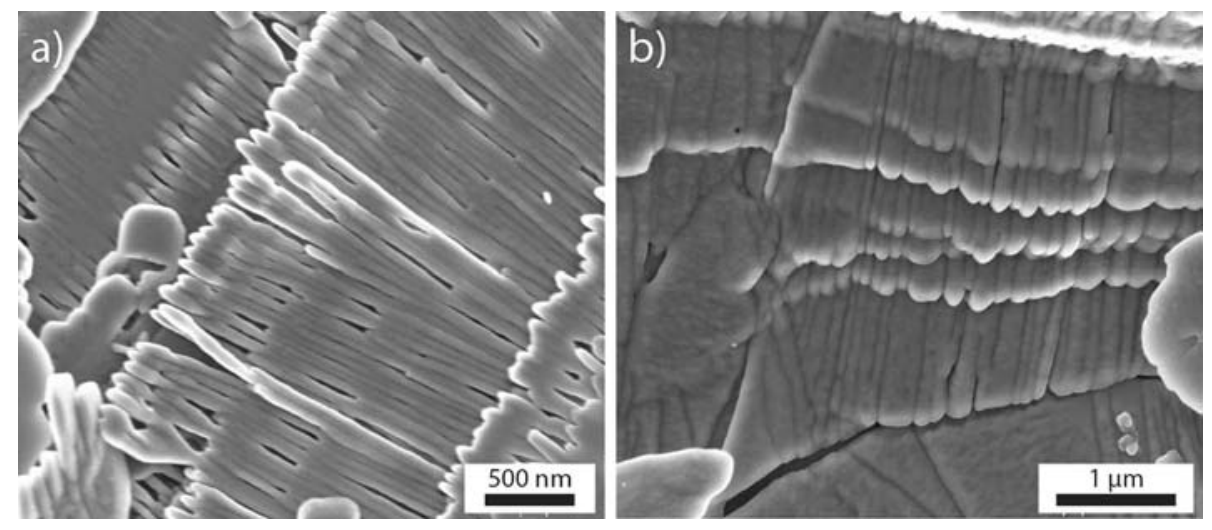

Fig. 4. FESEM observations of the particular orientation of the baryte crystals layer formed on top of the (010) gypsum surfaces (250 $\mathrm{mM} \mathrm{BaCl} 2$ ); after (a) 1 day; (b) 3 days.

$(5.674 \AA)$ closely match $\mathrm{Ba}-\mathrm{Ba}$ and $\mathrm{S}-\mathrm{S}$ distance in Bar (010) along [001] (5.458 ̊). On the other hand, epitactic relationships between the perpendicular gypsum striated surface and baryte layer could not be determined for the unknown nature of the surfaces originally present on these sides of the cut gypsum crystals. Any possible directional determination was beyond the limitations of the experimental diffraction technique.

Furthermore, the evolution of the degree of orientation during the transformation is also a key variable to consider during the mineral replacement reaction. The scattering or degree of preferential orientation of baryte crystals can be calculated from the intensity profile associated to a specific Debye-Scherrer ring (i.e., $h k l$ reflection). For this purpose, the individual 2D-XRD patterns were added (72 frames, $5^{\circ}$ step) to obtain the intensity profile of the $\psi$-scan $\left(360^{\circ}\right.$ rotation in the surface plane) along the Debye-Scherrer ring associated with the 020 reflection of the baryte replacement crystals. Figure 8 shows a progressive increase in the FWHM- $\phi$ values for the baryte 020 reflection with reaction time (from $12 \mathrm{~h}$ to 10 days). Taking this correlation into account, the preferential orientation relationship between the gypsum surface and the baryte replacement layer does uncouple, with increasing reaction time.

\subsection{Replacement process in polycrystalline gypsum cubes}

In the polycrystalline gypsum cubes $\left(10 \times 10 \times 10 \mathrm{~mm}^{3}\right)$, which are comprised of compacted grains of sizes $10-50 \mu \mathrm{m}$, the replacement process advanced toward the centre of the cube approximately $50 \mu \mathrm{m}$ (Fig. 9a) in $24 \mathrm{~h}$. The individual gypsum grains were replaced by a baryte layer of 2-7 $\mu \mathrm{m}$ in thickness (Fig. 9b). As in the singlecrystal experiments, the replacement process was stopped or slowed down considerably since no major advancement was observed at longer reaction times of 24-168 h. The EDX analyses (Fig. 9c) confirmed the distribution of barium and calcium in the reacted polycrystalline samples, corresponding to the replacing baryte layer and unreacted gypsum phase. The replacement layer was quite homogeneous, replacing partially the polycrystalline grains in the outer part of the gypsum cubes by the solution accessing the cubes via the grain boundaries. The FESEM observations on the surface of the reacted cubes showed that, at shorter reaction times $(5 \mathrm{~h})$, gypsum grains were partially coated by baryte nanoparticles of approximately $100-200 \mathrm{~nm}$ in size (Fig. 10a). At longer reaction times (1 day), grains were completely coated by a homogeneous 


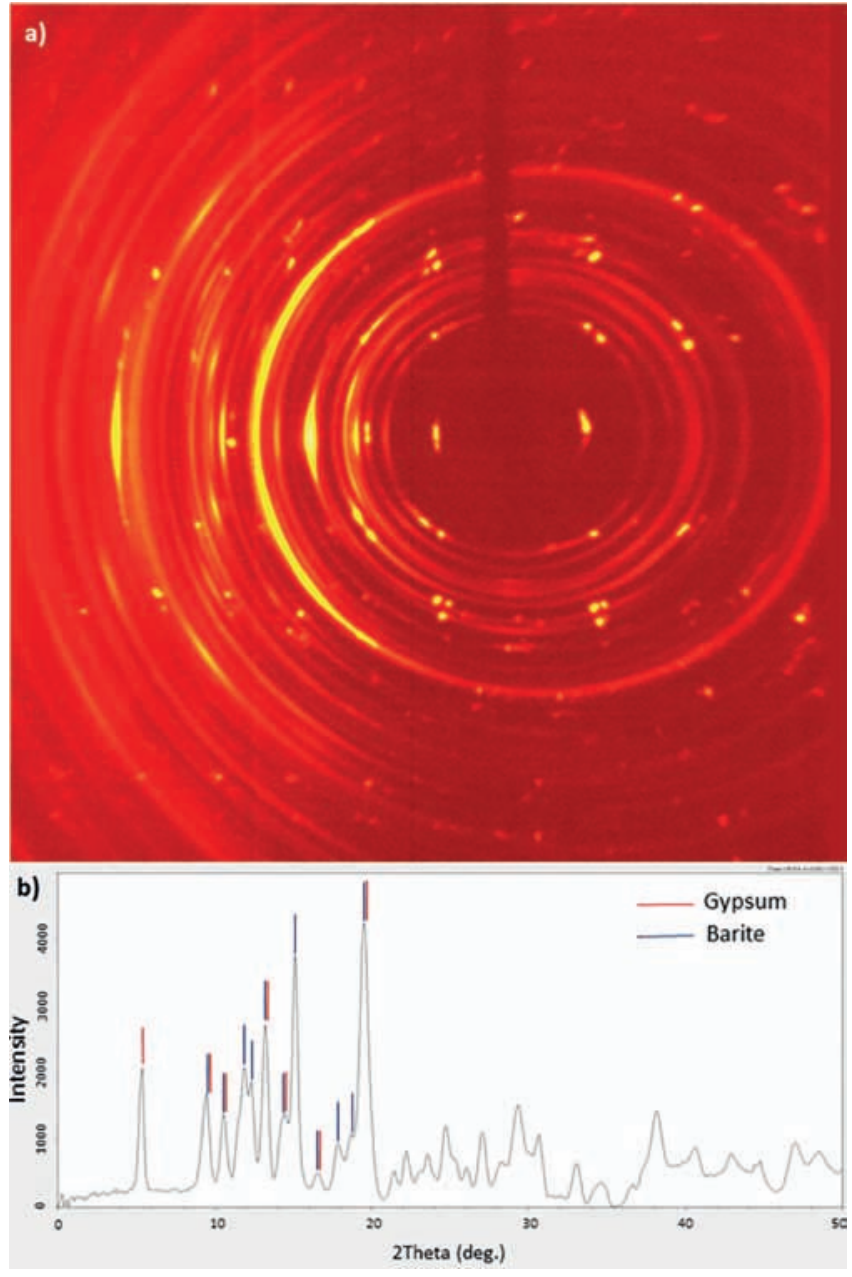

Fig. 5. Two-dimensional X-ray diffraction (2D-XRD) analyses. (a) 2D-XRD pattern (phi-rotation scan) from the gypsum cleavage surface (strong single crystal spots) with baryte crystals of the replaced layer (Debye-Scherrer diffraction rings). The intensities are concentrated in arcs within the diffraction rings, indicating that a fraction of baryte crystals has a preferential crystallographic orientation. (b) $2 \theta$ scan profile obtained from the radial integration of the 2D-XRD pattern for gypsum (Gyp) and baryte (Bar) crystals.

baryte layer composed of the same type of nanoparticles (Fig. 10b). The thickness of the baryte layer agrees well with the replacement layer formed on the striated gypsum surfaces that are randomly oriented, similar to the polycrystalline surfaces.

\section{Discussion}

Overall, the external volume of the gypsum single crystals and the polycrystalline cubes is well preserved, indicating that the dissolution of gypsum was coupled with the precipitation of baryte both spatially and temporally. This coupling is probably caused by the interplay between the dissolution of a thin layer of gypsum resulting in the substrate-assisted nucleation of baryte, aided by the (010) gypsum surface and the chemical composition of the fluid at the interface of the gypsum. When a Ba-bearing fluid (undersaturated with

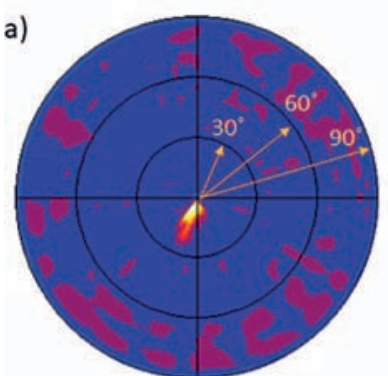

(020) Gyp

c)

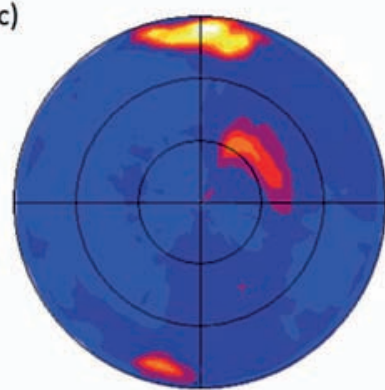

(200) Bar+ (011) Bar

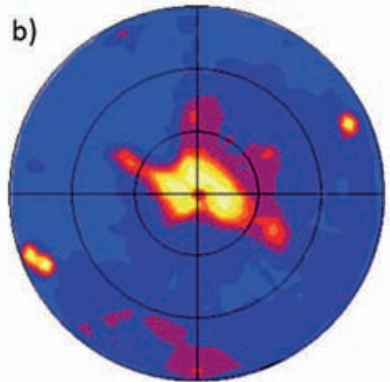

(020) Bar+(301) Bar

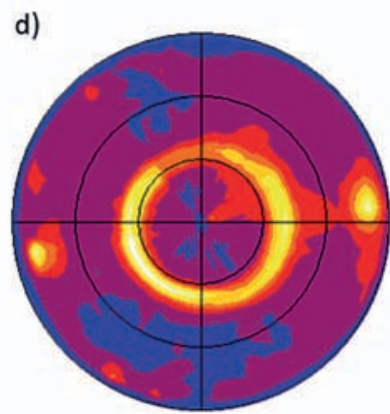

(303) Bar+ (321) Bar
Fig. 6. Pole figures (PFs) obtained from 2D-XRD analyses showing the crystallographic relationships between the gypsum surface and the baryte crystals of the replaced layer. Yellow lines indicate the angle distance from the centre to each black line circle representation in the PF. (a) PF for the 020 gypsum reflection with a centred maximum indicating that the surface is oriented in the same plane. (b) PF for the combined 020 and 301 reflections of the baryte crystals showing a centred maximum corresponding to the 020 reflection and two maxima related to the 301 reflection and tilted approximately $90^{\circ}$. (c) PF for the combined $200+011$ reflections of baryte crystals displaying two maxima corresponding to the 200 reflection tilted by approximately $90^{\circ}$ and a maximum tilted by approximately $37^{\circ}$ from the PF centre, in relation to the 020 baryte orientation. (d) PF for the combined $303+321$ reflections of baryte crystals displaying two maxima corresponding to the 303 reflection tilted by approximately $90^{\circ}$ and a circular sector corresponding to 321 reflection and tilted by $45^{\circ}$ from the 020 baryte orientation (PF centre).

respect to gypsum) interacts with a gypsum surface, gypsum starts to dissolve and hence calcium and sulfate ions are released to the fluid. As a result, supersaturation with respect to baryte is generated in the interfacial fluid, allowing baryte layers to precipitate on the gypsum surface.

\subsection{Gypsum single crystals}

The replacement process advanced greatly in the direction perpendicular to the (010) gypsum surfaces, comparing with striated surfaces. However, the reduction of porosity towards the inner part of the crystal seems to slow down considerably (or stop) the replacement reaction. The deeper within the replaced crystal, the slower the reaction kinetics as the reaction progress is dependent on the diffusion of species within the fluid phase up to and away from the reaction interface. The formation of connected porosity within the replacement layer is essential for allowing the reaction front 
a)

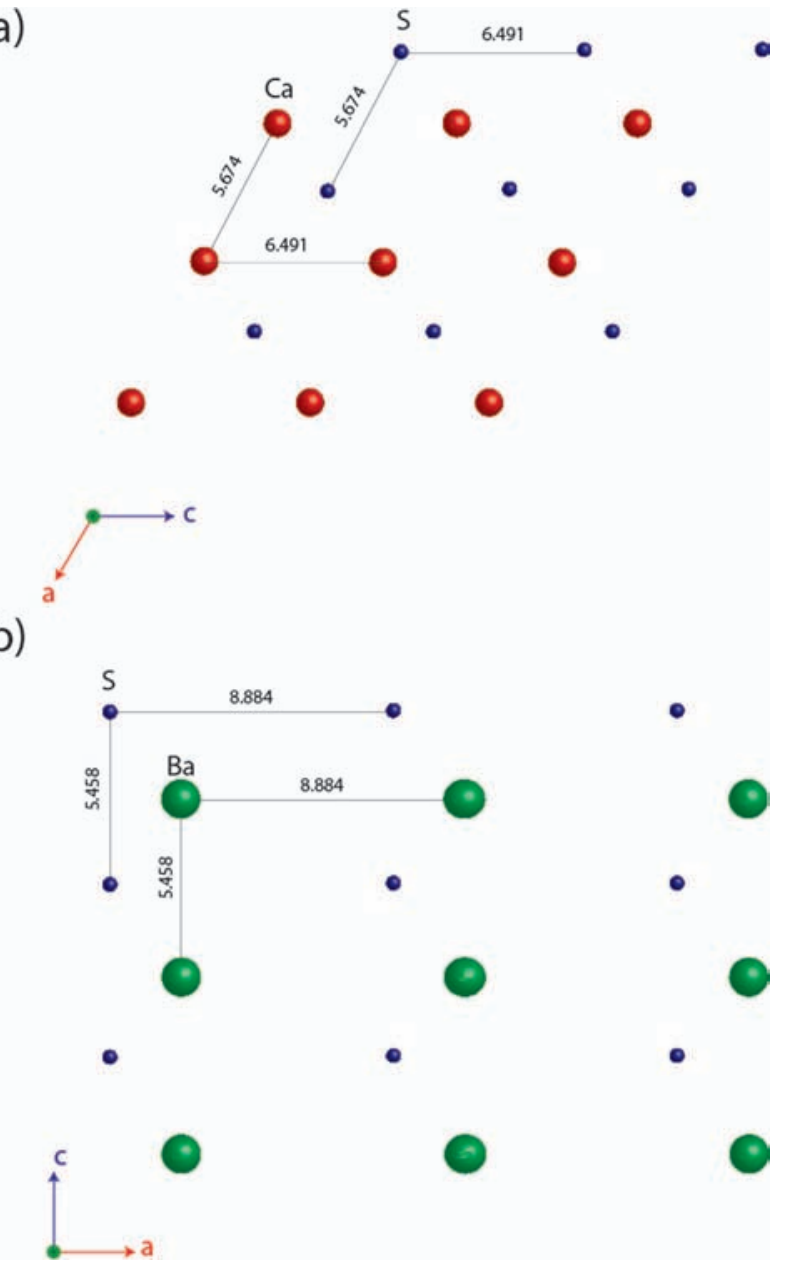

Fig. 7. Schematic projections of the crystal structures of a slice of (a) Gyp (010) and (b) Bar (010) (oxygen atoms are excluded in the representation for the sake of clarity). $\mathrm{Ca}, \mathrm{Ba}$ and $\mathrm{S}$ are depicted by red, green and blue spheres, respectively.

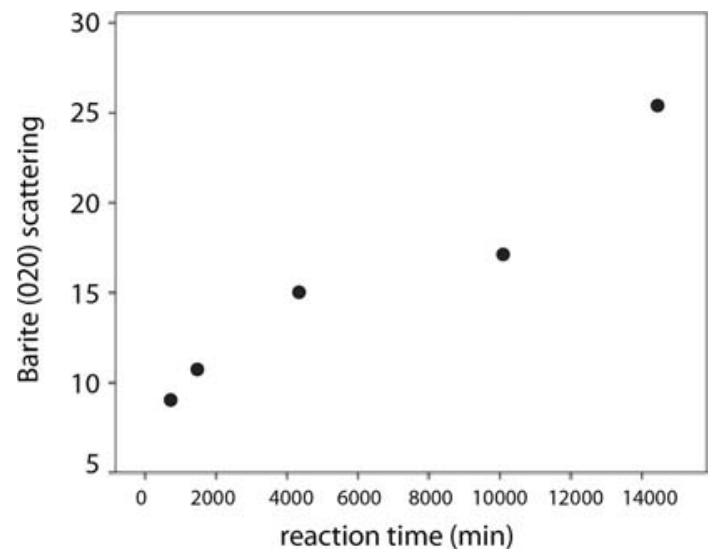

Fig. 8. Baryte crystals scattering (degree of orientation) obtained from the intensity profile along the Debye-Scherrer diffraction ring for 020 reflection.

to move towards the inner part of the crystal (Putnis et al., 2005). Porosity can be generated in a replacement reaction due to the differences in molar volume between parent and product phase and the relative solubility of the mineral phases in the interfacial fluid (i.e., ratio between dissolved material and precipitated material; Pollok et al., 2011). Interestingly, Zhao et al. (2014a and b) reported the generation of porosity in a replacement reaction with a large volume increase, underlining the low predictability of porosity development. Theoretically, taking into account the molar volume $\left(V_{\mathrm{m}}\right)$ of the two mineral phases, there would be a 35\% reduction during the replacement reaction $\left(V_{\mathrm{m} \text { Gypsum }}=73.84 \mathrm{~cm}^{3} / \mathrm{mol}\right.$ and $\left.V_{\mathrm{m} \text { Baryte }}=47.95 \mathrm{~cm}^{3} / \mathrm{mol}\right)$; however, this reduction would be even larger by taking into account the anisotropy of the two materials and the difference along the main surfaces involved in the replacement Gyp (010) and Bar (010) (15.7 $\AA$ in gypsum vs. $7.15 \AA$ in baryte for the same number of formula units). Porosity annealing during replacement reactions has been previously reported; however, in contrast to the observations presented here, the recrystallization that removes porosity operated from the outside of the crystal towards the centre (Putnis et al., 2005). While a conclusive explanation for the porosity decay in our system remains unknown, we propose that this could be due to the changes in the ratio between precipitated and dissolved material in the inner part of the replacement front, meaning that more baryte is formed than gypsum is dissolved in some specific locations of the replaced layer. The epitactic relationship acts as a promoter of the nucleation and growth of $\mathrm{BaSO}_{4}$; the high reactivity at the surface could generate a local depletion of sulfate ions and a gradient with the surrounding solution enriched by the other more reactive part of the gypsum single crystal. The transport of dissolved sulfate species from more reactive parts of the gypsum crystal to less reactive parts (less reactive for dissolution, i.e., $F$-faces, but more reactive for precipitation because the epitaxy reduces the energetic barrier required by the formation of the replacing phase) would assist this process, yielding to a significant decay in the porosity of the baryte layer (Fig. 1d and e) and in the replacement progress.

The role of the fluid phase, which allows transfer of chemical constituents to and from the reaction site, is crucial in replacement reactions but unfortunately extremely difficult to assess at the replacement front. Nevertheless, Ca concentration on the bulk increases with time due to the dissolution of the gypsum crystal until approximately $72 \mathrm{~h}$ and then decreases slightly. The reason for this decrease remains elusive; however, as stated in the methodology part, this is merely a qualitative assessment due to the differences in the gypsum crystals used for experiments. However, this is in agreement with our FESEM observations on reduction of permeability (Fig. 1c) and reinforces the hypothesis of a significant slowdown of the replacement process with time. Undetectable $\mathrm{S}$ concentrations in most of the experiments confirm the hypothesis that almost total reprecipitation occurred in the newly formed baryte layer.

The differences in porosity and morphology of the baryte layer in the direction perpendicular to the (010) gypsum surface and in the striated surfaces of the crystal were significant. These variations are probably related to the crystallographic structural control exerted by the gypsum 

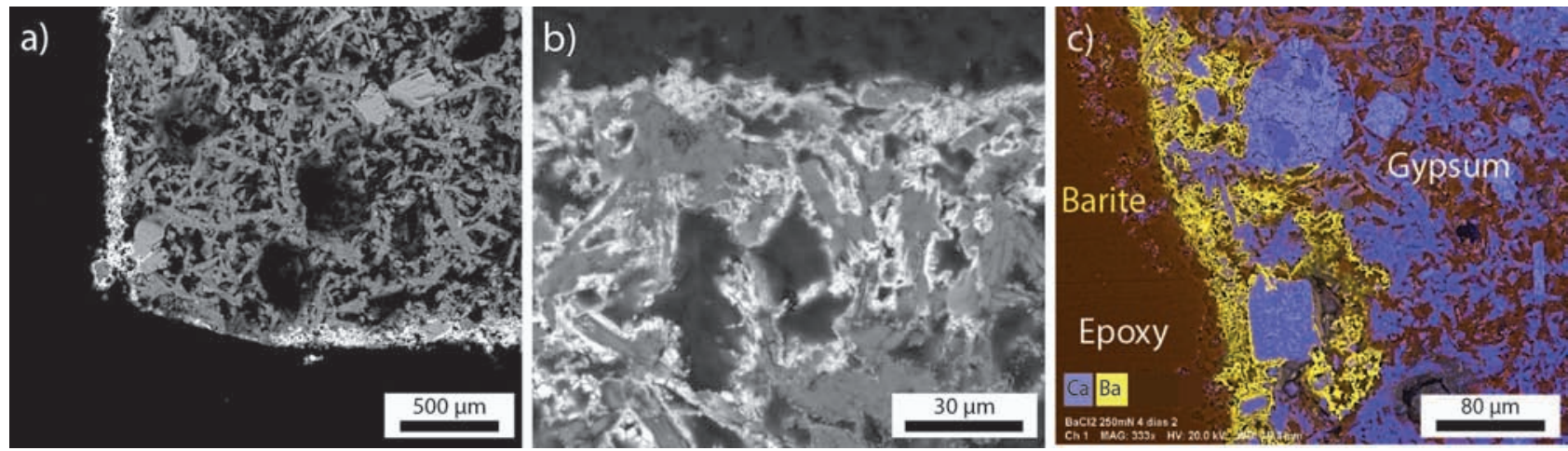

Fig. 9. BSE images of cross sections of partially replaced polycrystalline gypsum samples. (a) The baryte layer (white rim) penetrates inside the polycrystalline cube approximately $50 \mu \mathrm{m}$. (b) Higher magnification of the baryte layer covering gypsum grains. (c) Calcium and barium EDX maps showing the distribution of the baryte layer within the polycrystalline samples.
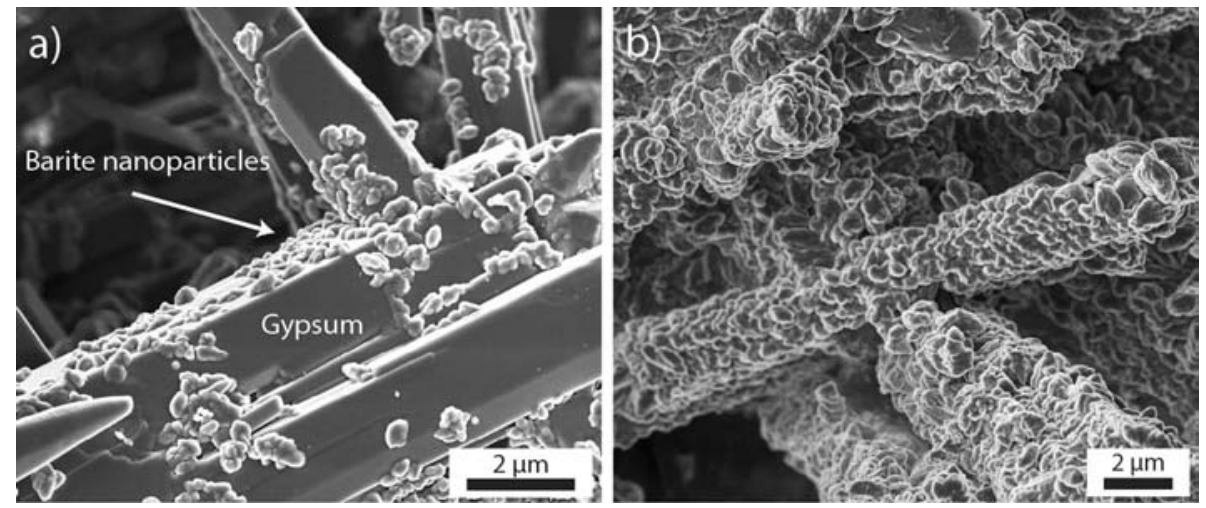

Fig. 10. FESEM images of a fresh cut of gypsum polycrystalline cubes replaced partially by baryte. Baryte nanoparticles of $100-200$ nm in size were (a) partially coating gypsum prisms $(5 \mathrm{~h})$ or (b) covering them completely at longer reaction times (1 day).

(010) surface on baryte nucleation and subsequent epitactic growth, which is hindered due to lack of crystallographic epitaxy on the striated surfaces. For several mineral systems, the influence of crystallographic relationships in the development of mineral replacement processes has been demonstrated. For instance, the crystallographic similarities between pentlandite and violarite (Xia et al., 2009) enable epitactic nucleation and foster the replacement. Recent investigations in the anhydrite-calcite system (Cuesta Mayorga et al., 2018) showed considerable differences between the calcite crystals grown on three anhydrite cleavages surfaces, highlighting the role of epitactic relationships on the replacement. In the case presented here, it seems logical to attribute the differences in the progress of the replacement along different surfaces to the epitactic relationships between gypsum and baryte structures (see below), which decrease the energy barrier for baryte nucleation on Gyp (010) in comparison to the striated surfaces.

Comparable systems have been studied previously such as the carbonation of gypsum (Fernández-Díaz et al., 2009) and the replacement of anhydrite by calcite (Roncal-Herrero et al., 2017; Cuesta Mayorga et al., 2018). Some similarities and differences exist with the results presented here. The replacement of gypsum by $\mathrm{CaCO}_{3}$-phases is characterized by the absence of epitactic relationships since it proceeds via the formation of an amorphous phase (ACC) and subsequent solvent-mediated transformation to vaterite and calcite. Contrary to our case, the replacement process on the "striated gypsum surfaces" was slightly enhanced compared with the replacement perpendicular to (010), which the authors attribute to higher reactivity of those artificially created surfaces. This difference with the baryte-gypsum system could be due to the effect of epitactic relationships (absent in the case of ACC formation) on lowering the energy barrier for baryte nucleation on Gyp (010), which does not occur on the striated surfaces. It was also observed that the replacement rate is significantly slowed down, most likely due to a decrease in permeability in the newly formed $\mathrm{CaCO}_{3}$ layer. Through a wide range of carbonate concentrations, the difference in thickness of the replacement layer between 24 and $72 \mathrm{~h}$ was almost inexistent. This is in good agreement with the results presented here where a comparable slow-down in the replacement process seems to be also caused by the reduction of permeability in the replaced layer. Interestingly, in the anhydrite-calcite replacement there were epitaxial relationships between the two surfaces and the dissolution behaviour was different between gypsum and anhydrite, which could explain the differences observed during the replacement reactions. 


\subsection{Polycrystalline cubes}

Preservation of the external volume was also found when polycrystalline gypsum cubes are replaced by baryte. The $\mathrm{BaSO}_{4}$ layer on polycrystalline samples resembles the layer formed on the striated gypsum surfaces, which are randomly oriented, analogous to the polycrystalline surfaces. The natural morphology of gypsum (Aquilano et al., 2016) is dominated by the $\{010\}$ crystal surface (cleavage surfaces), and may exhibit other equilibrium $F$ forms $\{120\},\{011\}$ and $\{111\}$, as well as other stepped forms ( $S$ forms) $\{100\},\{12 \overline{2}\},\{140\},\{180\}$, along with the kinked $\{102\}$ form ( $K$ form). These overall crystal morphologies come into play during the replacement reaction in the gypsum polycrystalline cubes. The dissolution behaviour of these gypsum surfaces and their different structural matching with baryte replacement crystals during reaction may influence the progress of mineral replacement on polycrystalline samples. These mechanisms can determine the interface-coupled dissolution-precipitation progress in the polycrystalline gypsum cubes - and its potential application as a plaster conservation method. Thus, further characterization of the replacement of gypsum by baryte on these other gypsum surfaces should be the target of future studies.

\section{Conclusion and implications}

This study shows that the mineral replacement of gypsum by baryte is a coupled dissolution-precipitation process in which the external shape of the original gypsum (both single crystals and polycrystalline) is preserved. When gypsum is in contact with a Ba-bearing solution, baryte cohesive layers can be formed on the gypsum (010) surface due to the coupling between gypsum dissolution and baryte precipitation in space and time. Moreover, the investigations on the replacement of gypsum single crystals showed that the (010) surface controls the preferential orientation of the baryte crystals formed during the replacement process. There was an evolution of the porosity generated within the baryte-replaced layer, coarsening at the outer edge and it seemed to close eventually, impeding the advancement of the replacement. Complementary studies conducted on polycrystalline gypsum samples also showed the formation of baryte layers that preserve the external shape of the original gypsum grains. The passivation of the replacement process, probably due to a significant reduction of the porosity in the newly formed baryte layer (as in the single-crystal case) would be an optimal feature aiming at gypsum plaster conservation. Due to the low solubility of baryte, this newly formed layer could protect the original gypsum plaster against water and humidity, while still preserving the original form of the gypsum substrate.

Pseudomorphic replacement reactions are presented here as a potential conservation method for gypsum plasters. The results of this study set the starting point for the design of baryte protective treatments for gypsum plasters. However, further investigation needs to be conducted to tune the baryte replacement layer by modifying the conditions of the reactant fluid. In addition, mechanical as well as dissolution studies on partially replaced samples are needed in order to confirm the resistance against dissolution and the low reactivity of the samples once they are partially replaced by a baryte layer.

Acknowledgements: This research was carried out within a Marie Curie initial training network from the European Commission (MINSC ITN 290040). The Deutsche Forschungsgemeinschaft (DFG) supports the research at the University of Münster. CRA and DG thank the SFB1214 and the Zukunftskolleg of the University of Konstanz for support. PAL acknowledges funding from CGL-2016-77138-C2-2P. We would like to also thank the personnel of the "Centro de Instrumentación Científica" (University of Granada) for their support and help with the ESEM, FESEM and 2D-XRD analyses. In addition, we would like to thank the Particle Analysis Center of the University of Konstanz (funded by SFB1214) for XRD measurements. FDL thanks the Spanish Government (grants CGL2015-70642-R, CGL2015-73103-EXP), the University of Granada ("Unidad Científica de Excelencia" UCE-PP2016-05) and the Junta de Andalucía (grants P11RNM-7550 and Research Group RNM-179). All the authors thank Christian Chopin and Carlos Rodríguez Navarro and the three anonymous reviewers for their insightful comments and effort towards improving this manuscript.

\section{References}

Ahmed, S.B., Tlili, M., Amor, M.B., Bacha, H.B., Elleuch, B. (2004): Calcium sulphate scale prevention in a desalination unit using the SMCEC technique. Desalination, 167, 311-318.

Alonso-Azcárate, J., Bottrell, S.H., Tritlla, J. (2001): Sulfur redox reactions and formation of native sulfur veins during low grade metamorphism of gypsum evaporites, Cameros Basin (NE Spain). Chem. Geol., 174, 389-402.

Alonso-Azcárate, J., Bottrell, S.H., Mas, J.R. (2006): Synsedimentary versus metamorphic control of $\mathrm{S}, \mathrm{O}$ and $\mathrm{Sr}$ isotopic compositions in gypsum evaporites from the Cameros Basin, Spain. Chem. Geol., 234, 46-57.

Álvarez-Lloret, P., Rodríguez-Navarro, A.B., Falini, G., Fermani, S., Ortega-Huertas, M. (2010): Crystallographic control of the hydrothermal conversion of calcitic sea urchin spine (Paracentrotus lividus) into apatite. Cryst. Growth Des., 10, 5227-5232.

Aquilano, D., Otálora, F., Pastero, L., García-Ruiz, J.M. (2016): Three study cases of growth morphology in minerals: halite, calcite and gypsum. Prog. Cryst. Growth Charac. Mat., 62, 227-251.

Blasco-López, F.J. \& Alejandre Sánchez, F.J. (2013): Porosity and surface hardness as indicators of the state of conservation of Mudéjar plasterwork in the Real Alcázar in Seville. J. Cult. Herit., 14, 169-173.

Bosbach, D. \& Rammensee, W. (1994): In situ investigation of growth and dissolution on the (010) surface of gypsum by Scanning Force Microscopy. Geochim. Cosmochim. Acta, 58, 843-849.

Buick, R. \& Dunlop, J.S.R. (1990): Evaporitic sediments of Early Archaean age from the Warrawoona Group, North Pole, Western Australia. Sedimentology, 37, 247-277. 
Buick, R., Thornett, J.R., McNaughton, N.J., Smith, J.B., Barley, M. E., Savage, M. (1995): Record of emergent continental crust $\sim 3.5$ billion years ago in the Pilbara craton of Australia. Nature, 375, 574-577.

Burgos-Cara, A., Putnis, C.V., Rodriguez-Navarro, C., RuizAgudo, E. (2016): Hydration effects on gypsum dissolution revealed by in situ nanoscale atomic force microscopy observations. Geochim. Cosmochim. Acta, 179, 110-122.

Cuesta Mayorga, I., Astilleros, J.M., Fernández-Díaz, L., Morales, J., Prieto, M., Roncal-Herrero, T., Benning, L.G. (2018): Epitactic overgrowths of calcite $\left(\mathrm{CaCO}_{3}\right)$ on anhydrite $\left(\mathrm{CaSO}_{4}\right)$ cleavage surfaces. Cryst. Growth Des., 18, 1666-1675.

Dominguez-Vidal, A., de la Torre-Lopez, M.J., Rubio-Domene, R., Ayora-Cañada, M.J. (2012): In situ noninvasive Raman microspectroscopic investigation of polychrome plasterworks in the Alhambra. Analyst, 137, 5763-5769.

Fan, C. \& Teng, H. (2007): Surface behavior of gypsum during dissolution. Chem. Geol., 245, 242-253.

Fernández-Díaz, L., Pina, C.M., Astilleros, J.M., Sánchez-Pastor, N. (2009): The carbonatation of gypsum: pathways and pseudomorph formation. Am. Mineral., 94, 1223-1234.

Freyer, D. \& Voigt, W. (2003): Crystallization and phase stability of $\mathrm{CaSO}_{4}$ and $\mathrm{CaSO}_{4}$-based salts. Monatsh. Chem., 134, 693-719.

Hall, C. \& Cullen, D.C. (1996): Scanning force microscopy of gypsum dissolution and crystal growth. AIChe J., 42, 232-238.

Hardie, L.A. (1967): The gypsum-anhydrite equilibrium at one atmosphere pressure. Am. Mineral., 52, 171-200.

Jroundi, F., Gonzalez-Muñoz, M.T., Garcia-Bueno, A., RodriguezNavarro, C. (2014): Consolidation of archaeological gypsum plaster by bacterial biomineralization of calcium carbonate. Acta Biomater., 10, 3844-3854.

Lambert, I.B., Donelly, T.H., Dunlop, J.S.R., Groves, D.I. (1978): Stable isotopic compositions of early Archean sulphate deposits of probable evaporitic and volcanogenic origins. Nature, 276, 808-811.

Lasaga, A.C. \& Luttge, A. (2001): Variation of crystal dissolution rate based on a dissolution stepwave model. Science, 291, 2400-2404.

Ostroff, A.G. (1964): Conversion of gypsum to anhydrite in aqueous salt solutions. Geochim. Cosmochim. Acta, 28, 1363-1372.

Parkhurst, D.L. \& Appelo, C.A.J. (1999): User's Guide to Phreeqc (version 2) - A computer program for speciation, batch-reaction, one-dimensional transport, and inverse geochemical calculations. U.S. Geological Survey Water-Resources 99-4259.

Pollok, K., Putnis, C.V., Putnis, A. (2011): Mineral replacement reactions in solid solution-aqueous solution systems: volume changes, reactions paths and end-points using the example of model salt systems. Am. J. Sci., 311, 211-236.

Prieto, M., Cubillas, P., Fernández-Gonzalez, Á. (2003): Uptake of dissolved $\mathrm{Cd}$ by biogenic and abiogenic aragonite: a comparison with sorption onto calcite. Geochim. Cosmochim. Acta, 67, 3859-3869.

Putnis, A. (2002): Mineral replacement reactions. Mineral. Mag., 66, 689-708.
- (2009): Mineral replacement reactions. Rev. Mineral. Geochem., 70, $87-124$

Putnis, A. \& Putnis, C.V. (2007): The mechanism of reequilibration of solids in the presence of a fluid phase. J. Solid State Chem., 180, 1783-1786.

Putnis, C.V., Tsukamoto, K., Nishimura, Y. (2005): Direct observations of pseudomorphism: compositional and textural evolution at a fluid-solid interface. Am. Mineral., 90, 1909-1912.

Regourd, M., Kerisel, J., Deletie, P., Haguenauer, B. (1988): Microstructure of mortars from three Egyptian pyramids. Cem. Concr. Res., 18, 81-90.

Rodriguez-Navarro, A.B. (2006): lit XRD2DScan: new software for polycrystalline materials characterization using two-dimensional X-ray diffraction. J. Appl. Crystallogr., 39, 905-909.

Roncal-Herrero, T., Astilleros, J.M., Bots, P., Rodríguez-Blanco, J. D., Prieto, M., Benning, L.G., Fernández-Díaz, L. (2017): Reaction pathways and textural aspects of the replacement of anhydrite by calcite at $25^{\circ} \mathrm{C}$. Am. Mineral., 102, 1270-1278.

Ruiz-Agudo, E., Putnis, C.V., Putnis, A. (2014): Coupled dissolution and precipitation at mineral-fluid interfaces. Chem. Geol., 383, 132-146.

Stewart, B.A. (1989): Advances in Soil Science. Springer US, New York, NY

Teng, F., Zeng, H., Liu, Q. (2011): Understanding the deposition and surface interactions of gypsum. J. Phys. Chem. C, 115, 17485-17494.

Van Driessche, A.E.S., García-Ruiz, J.M., Delgado-López, J.M., Sazaki, G. (2010): In situ observation of step dynamics on gypsum crystals. Cryst. Growth Des., 10, 3909-3916.

Van Driessche, A.E.S., Benning, L.G., Rodriguez-Blanco, J.D., Ossorio, M., Bots, P., Garcia-Ruiz, J.M. (2012): The role and implications of bassanite as a stable precursor phase to gypsum precipitation. Science, 336, 69-72.

Watson, A. (1979): Gypsum crusts in deserts. J. Arid Environ., 2, 3-20.

Xia, F., Brugger, J., Chen, G., Ngothai, Y., O’Neill, B., Putnis, A., Pring, A. (2009): Mechanism and kinetics of pseudomorphic mineral replacement reactions: a case study of the replacement of pentlandite by violarite. Geochim. Cosmochim. Acta, 73, 1945-1969.

Zen, E.-A. (1965): Solubility measurements in the system $\mathrm{CaSO}_{4-}$ $\mathrm{NaCl}-\mathrm{H}_{2} \mathrm{O}$ at $35^{\circ}, 50^{\circ}$, and $70^{\circ} \mathrm{C}$ and one atmosphere pressure. J. Petrol., 6, 124-164.

Zhao, J., Brugger, J., Chen, G., Ngothai, Y., Pring, A. (2014a): Experimental study of the formation of chalcopyrite and bornite via the sulfidation of hematite: mineral replacements with a large volume increase. Am. Mineral., 99, 343-354.

Zhao, J., Brugger, J., Ngothai, Y., Pring, A. (2014b): The replacement of chalcopyrite by bornite under hydrothermal conditions. Am. Mineral., 99, 2389-2397.

Received 10 May 2018

Modified version received 9 December 2018

Accepted 9 January 2019 